\section{The Metabolic Costs of Gardening Tasks in Children}

\author{
Sin-Ae Park ${ }^{1}$, Ho-Sang Lee ${ }^{1}$, Kwan-Suk Lee ${ }^{2}$, Ki-Cheol Son ${ }^{1,4}$, \\ and Candice A. Shoemaker ${ }^{3}$
}

ADDitional INDEX wORDs. Cosmed $\mathrm{K}^{4} \mathrm{~b}^{2}$, horticultural therapy, METs, physical activity, socio-horticulture

Summary. The metabolic cost of 10 gardening tasks was measured in children to determine the exercise intensities associated with these tasks. Seventeen children $\left[(\right.$ mean \pm SD $)$ aged $12.4 \pm 0.7$ years and body mass index $\left.21.6 \pm 4.0 \mathrm{~kg} \cdot \mathrm{m}^{-2}\right]$ participated in this study. The children performed the 10 gardening tasks at a garden previously established in Cheongju, Chungbuk, South Korea. They visited the garden twice and performed five different tasks on each visit. Five minutes were provided to complete each gardening task and a 5-minute rest was allowed between each task. The children wore a portable telemetric calorimeter and a heart rate monitor for measurement of oxygen uptake and heart rate during the gardening tasks. The results show that the 10 gardening tasks represented moderate- to highintensity physical activity for the children $[4.3 \pm 0.5$ to $6.6 \pm 1.6$ metabolic equivalents $(\mathrm{MET})]$. Digging $(6.6 \pm 1.6 \mathrm{MET})$ and raking $(6.2 \pm 1.5 \mathrm{MET})$ were high-intensity physical activities, and digging was more intense than the other gardening tasks performed in this study $(P<0.05)$. Tasks such as weeding $(5.8 \pm$ $1.1 \mathrm{MET})$, mulching $(5.5 \pm 1.3 \mathrm{MET})$, hoeing $(5.3 \pm 0.7 \mathrm{MET})$, sowing seeds $(5.0 \pm 1.1 \mathrm{MET})$, harvesting $(4.8 \pm 0.6 \mathrm{MET})$, watering $(4.6 \pm 1.1 \mathrm{MET})$, mixing growing medium $(4.4 \pm 0.6 \mathrm{MET})$, and planting transplants $(4.3 \pm 0.5 \mathrm{MET})$ were moderate-intensity physical activities. The MET data for the gardening tasks will facilitate the development of garden-based exercise interventions for children, which can promote health and physically active lifestyle.

$\mathrm{P}$ hysical activity is "bodily movement that is produced by the contraction of skeletal muscle and that substantially increases energy expenditure" [U.S. Department of Health and Human Services (HHS), 1996]; this definition includes incidental physical activity, such as housework and walking for transportation (Caspersen et al., 1985). Metabolic equivalents are used to express the exercise intensity associated with a physical activity (Norton et al., 2010). The MET value for a specific physical activity can be determined on the basis of the oxygen consumption per unit of body mass while performing the activity $\left[1 \mathrm{MET}=3.5 \mathrm{~mL} \cdot \mathrm{kg}^{-1} \cdot \mathrm{min}^{-1}\right.$ oxygen (Norton et al., 2010)]. The intensity of physical activities can be classified as low (less than 3 MET), moderate ( 3 to $6 \mathrm{MET}$ ), and high

This paper was supported by the SMART Research Professor Program of Konkuk University.

${ }^{1}$ Department of Environmental Health Science, Konkuk University, Seoul 143-701, South Korea

${ }^{2}$ Department of Industrial Engineering, Hongik University, Seoul 121-791, South Korea

${ }^{3}$ Department of Horticulture, Forestry, \& Recreation Resources, Kansas State University, KS 66506

${ }^{4}$ Corresponding author. E-mail: kcson@konkuk.ac.kr. (higher than 6 MET) (Pate et al., 1995). For example, the resting metabolic rate, which is recorded while one is lying down, is I MET, sitting quietly is 1.3 MET, walking for pleasure involves 3.5 MET as a moderateintensity activity, and jogging involves 7.5 MET as a high-intensity activity (Ainsworth et al., 2011).

Despite the health benefits of physical activity, many children have low physical activity levels and a sedentary lifestyle (Taveras et al., 2007). Physical inactivity in childhood may lead to a sedentary lifestyle in adulthood (Malina, 2001; Telama et al., 1997), increasing the risk for diseases in the future (HHS, 1996). The barriers to physical activity in children are: a preference for indoor activities such as viewing television or playing video/ computer games, time constraints, unsafe neighborhoods, a lack of motivation, hesitation caused by perceived incompetence or lack of skill, a lack of resources, and insufficient social support from parents and peers (Burdette and Whitaker, 2005; Norman et al., 2005; O'Dea, 2003; Rees et al., 2006; Spear et al., 2007; Taveras et al., 2007). Thus, to encourage participation in regular physical activity, effective strategies are needed. In particular, factors such as enjoyment and fun are important components to keep children motivated and interested in participating in an intervention (Baranowski et al., 2008; Borra et al., 1995; Epstein et al., 2007; Mellecker and McManus, 2008). Children may show an improvement in health conditions such as type 2 diabetes and obesity by meeting the physical activity recommendations for health benefits; i.e., at least $60 \mathrm{~min}$ of daily moderate- to vigorous-intensity physical activity (Biddle et al., 1998; Bundred et al., 2001; Department of Health, 2004; London and Gurantz, 2013; McCue et al., 2013; Siwik et al., 2013; Stamatakis et al., 2005; Strong et al., 2005).

Gardening provides a hands-on experience in the process of growing plants and helps children understand the life cycle of plants and the ecosystem (Montessori, 1964; Morris et al., 2000). Gardening is a dynamic activity because of seasonal variations and plant growth cycles (Park et al., 2008a); therefore, it may maintain children's interest and curiosity. Moreover, school gardening has been reported to elicit positive effects, such as improved science achievement (Dirks and Orvis, 2005; Klemmer et al., 2005a, 2005b; Mabie and Baker,1996; Smith and Motsenbocker, 2005) and eating habits, including increased fruit and vegetable intake (Lineberger and Zajicek,

\begin{tabular}{llll}
\hline $\begin{array}{l}\text { Units } \\
\text { To convert U.S. to SI, } \\
\text { multiply by }\end{array}$ & U.S. unit & SI unit & $\begin{array}{l}\text { To convert SI to U.S., } \\
\text { multiply by }\end{array}$ \\
\hline 9.2303 & calorie(s)/lb & $\mathrm{kJ} \cdot \mathrm{kg}^{-1}$ & 0.1083 \\
0.3048 & $\mathrm{ft}$ & $\mathrm{m}$ & 3.2808 \\
2.54 & inch $(\mathrm{es})$ & $\mathrm{cm}$ & 0.3937 \\
36.1273 & inch $^{3} / \mathrm{lb}$ & $\mathrm{mL} \cdot \mathrm{kg}^{-1}$ & 0.0277 \\
0.4536 & lb & $\mathrm{kg}$ & 2.2046 \\
4.8824 & $\mathrm{lb} / \mathrm{ft}^{2}$ & $\mathrm{~kg} \cdot \mathrm{m}^{-2}$ & 0.2048 \\
1.6093 & $\mathrm{mph}$ & $\mathrm{km} \cdot \mathrm{h}^{-1}$ & 0.6214 \\
28.3495 & $\mathrm{OZ}$ & $\mathrm{g}$ & 0.0353 \\
$\left({ }^{\circ} \mathrm{F}-32\right) \div 1.8$ & ${ }^{\circ} \mathrm{F}$ & ${ }^{\circ} \mathrm{C}$ & $\left({ }^{\circ} \mathrm{C} \times 1.8\right)+32$
\end{tabular}

Hortlechnology $\cdot$ October $201323(5)$ 
2000; McAleese and Rankin, 2007; Morris et al., 2001, Morris and Zidenberg-Cherr, 2002) in children.

In previous studies, gardening was determined to be a physical activity that can involve energy expenditure (Park et al., 2008a, 2008b, 2011, 2012a, 2012b). Various common gardening tasks, such as digging, raking, planting, mulching, harvesting, and watering, were low- to moderateintensity physical activities in older adults over 65 years of age. Most of the gardening tasks that were tested in older adults were moderate-intensity physical activities in adults in their twenties (Park et al., 2012a). In Ainsworth et al. (2011), $\approx 30$ of the lawn and gardening tasks were classified as moderate-intensity physical activities in adults below 65 years of age, on the basis of published or estimated data. However, there is not enough data on the metabolic costs of gardening tasks, especially in children. Therefore, the metabolic costs of these tasks were measured to determine the corresponding exercise intensities and effectiveness of these tasks as a physical activity in children. The results can be used to develop a gardening program for children to achieve proper levels of physical activity for health benefits.

\section{Materials and methods}

Participants. Children between 11 and 13 years of age were recruited from the community in Cheongju, Chungbuk, South Korea. The children aged 11 to 13 years were targeted in this study because of the availability of the measurement tool (i.e., small, medium, and large sizes of the facemask for the metabolic cost measurement are provided. The small size is available for the higher-grade elementary school children). A flyer with a description of the purpose, requirement, time schedule, etc., of this study and a registration form were distributed at churches, community centers, and directly to individuals by acquaintances. The flyer was also posted on bulletin boards in residential areas. Criteria required that participants in this study be between 11 and 13 years of age and free of known diseases. A written informed consent form from the children's parents or caregivers was also required for participation in this study. Seventeen Korean children (13 boys, 4 girls) volunteered for this study and the sample size of 17 was statistically large enough to generalize to the population of interest. The average age and body mass index was (mean $\pm \mathrm{SD}$ ) $12.4 \pm$ 0.7 years and $21.6 \pm 4.0 \mathrm{~kg} \cdot \mathrm{m}^{-2}$, respectively. The children were requested to not eat a heavy meal and to not perform physical activity before at least $12 \mathrm{~h}$ of testing. They were also instructed to wear proper clothes, shoes, and gloves for gardening. As an incentive, each child received a gift card (US\$10) at the completion of all test sessions.

EXPERIMENTAL PROCEDURES. Ten gardening tasks, namely, digging, raking, weeding, mulching, hoeing, sowing seeds, harvesting, watering, mixing growing medium, and planting transplants, were conducted by the children in a high tunnel which is a shade area and a grassy area located next to the high tunnel; both sites were located in Cheongju, Chungbuk, South Korea (Table 1). The researchers sectionalized the grassy area for weeding and previously cultivated the vegetables such as lettuce (Lactuca sativa) and korean sesame leaf (Perilla frutescens var. crispa) for harvesting near the high tunnel. The children visited the garden plot twice and conducted five different garden tasks during each visit. The researchers drew lots to randomly decide the order of gardening tasks for each child.

Five minutes were provided for each gardening task, and a 5-min rest was given between each task, during which the child was required to sit on a chair. The amount of time for the gardening task and rest was previously determined to be enough for metabolic measurement of gardening tasks in a preliminary study (Park et al., 2011). In the study, 5 min for activity or resting was sufficient to measure the metabolic costs and recover heart rate to its resting rate. Throughout the entire test session, the children wore the measurement tools for measuring metabolic cost and were asked to not speak. During the resting period, the researchers demonstrated or verbally explained the next gardening task. All measures of the 10 gardening tasks were completed in the morning or last afternoon of Aug. 2012. The weather conditions during the test were an average temperature of (mean \pm SD) $29.6 \pm 5.4^{\circ} \mathrm{C}$ and a humidity of $76.5 \pm 17.2 \%$ (Acuba
CS-201 Digital Hygro-Thermometer; Chosun, Guangdong, China).

Evaluation OF THE METABOLIC COSTS OF GARDENING TASKS. To measure the metabolic costs of gardening tasks, in terms of oxygen uptake, energy expenditure, and MET, each child wore a portable telemetric calorimeter $\left(\mathrm{K}_{4} \mathrm{~b}^{2}\right.$; Cosmed, Rome, Italy) that consists of a portable telemetric transmitter, facemask, flow meter, gas analyzer, receiver, and temperature probe (HR-TEMP). The $\mathrm{K} 4 \mathrm{~b}^{2}$ is a portable system and is useful for measuring outdoor activities. It has validity and accuracy equal to those of the Douglas bag method, which is generally considered to be the most accurate means of indirect calorimetry but is impractical in outside laboratory settings (Doyon et al., 2001; Kawakami et al., 1992; McLaughlin et al., 2001). The children respired into the facemask during the entire test session to allow measurement of their oxygen uptake, and the data were continuously recorded with individual points representing averaged 3 -s intervals. For collection of heart rate data while gardening, the children wore a heart rate monitor (Polar T 31; FitMed, Kempele, Finland) under their breast.

Weight, body composition [fat (grams), lean mass (grams), and percent fat], and height without shoes were measured by a body fat analyzer (ioi 353; Jawon Medical, Gyeongsan, South Korea) and an anthropometer (Ok7979; Samhwa, Seoul, South Korea), which is a well-used height measurement tool. Weight and height data were used to calculate body mass index $\{$ body mass index $=[$ weight (kilograms) $\left.] /[\text { height (meters) }]^{2}\right\}$. On the first visit, before starting the first test session, the children sat on a chair for $5 \mathrm{~min}$ for measurement of their resting metabolic rate and heart rate. The age-adjusted maximum heart rate was calculated by the equation $208-$ $0.7 \times$ age (Tanaka et al., 2001). Ageadjusted heart rate presents basic information for subjects in studies about metabolic costs of activities (Gunn et al., 2005). Maximum heart rate is the highest number of times heart can contract in $1 \mathrm{~min}$ and it is the most useful tool for determining training intensities because it can be measured or predicted for individuals (Atwal et al., 2002).

Data analysis. Descriptive information was managed using Excel 
Table 1. Description of 10 gardening tasks performed by children aged 11 to 13 years in a study to determine exercise intensities of gardening tasks.

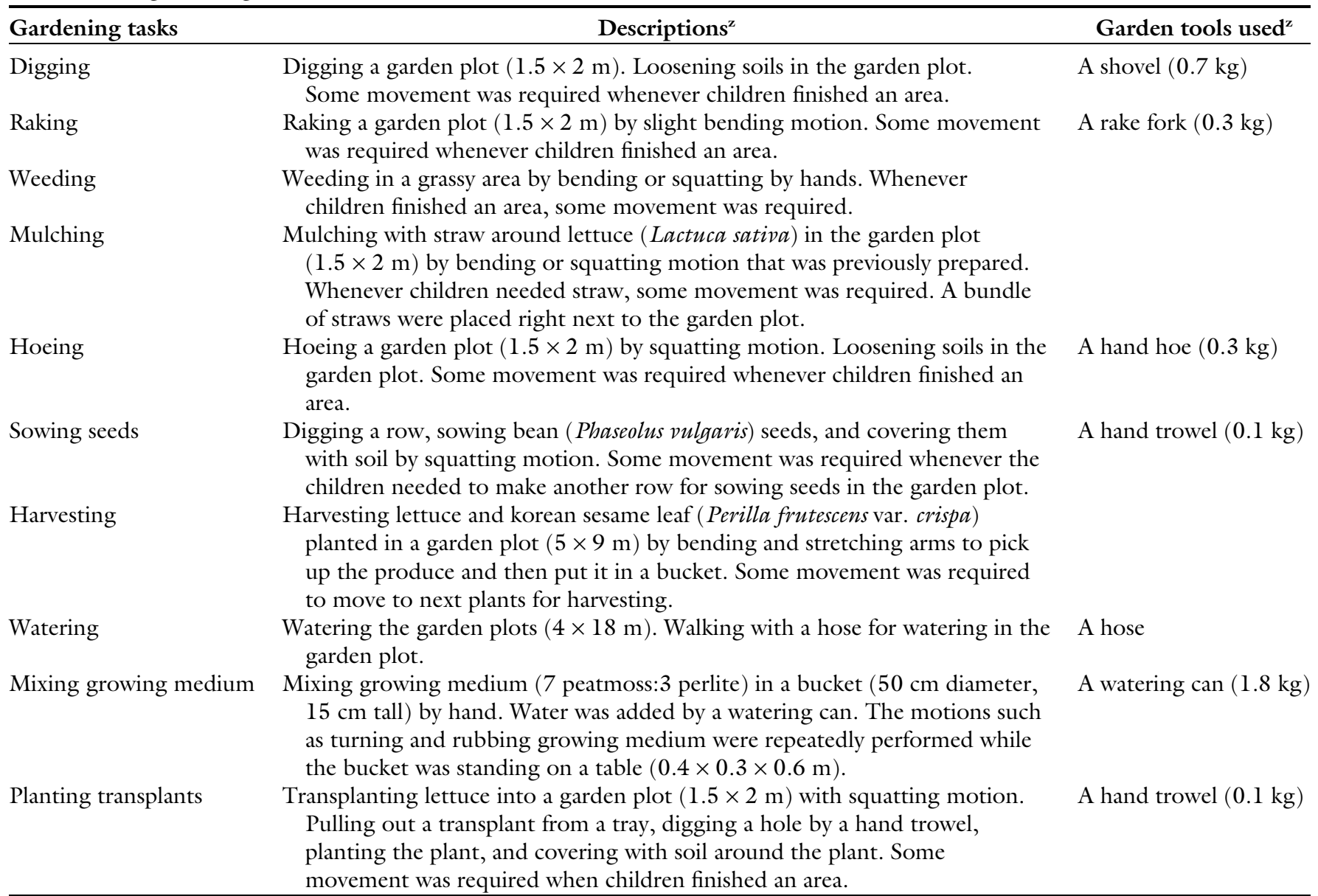

${ }^{\mathrm{z}} 1 \mathrm{~m}=3.2808 \mathrm{ft}, 1 \mathrm{~cm}=0.3937 \mathrm{inch}, \mathrm{l} \mathrm{kg}=2.2046 \mathrm{lb}$.

(Office 2007; Microsoft Corp., Redmond, WA). A one-way analysis of variance (ANOVA) F test was conducted to compare the means of metabolic cost parameters such as oxygen uptake, energy expenditure, MET, and heart rate for the 10 gardening tasks at $P<0.05$ using SPSS (version 18 for Windows; IBM, Armonk, NY). When the results of the ANOVA test were statistically significant, Scheffé posthoc test was conducted to determine where differences between the means of metabolic cost parameters at $P<0.05$. Data for the first $10 \mathrm{~s}$ were deleted to compensate for the time required to walk to the garden plot and start a gardening task.

\section{Results and discussion}

Seventeen Korean children aged 11 to 13 years and in the normal range for body mass index [ (mean \pm SD ) $21.6 \pm 4.0 \mathrm{~kg} \cdot \mathrm{m}^{-2}$ ] participated in this study (Table 2 ). The 10 common gardening tasks performed by the children were moderate- to highintensity physical activities $(4.3 \pm 0.5$ to $6.6 \pm 1.6 \mathrm{MET}$ ) (Table 3 ) (Norton et al., 2010; Pate et al., 1995). Digging (6.6 $\pm 1.6 \mathrm{MET})$ and raking $(6.2 \pm 1.5 \mathrm{MET})$ were highintensity physical activities for the children, and digging was more intense than the other gardening tasks performed in this study $(\mathrm{F}=8.62, P<$ $0.0001)$. Weeding $(5.8 \pm 1.1 \mathrm{MET})$, mulching $(5.5 \pm 1.3 \mathrm{MET})$, hoeing $(5.3 \pm 0.7 \mathrm{MET})$, sowing seeds (5.0 \pm $1.1 \mathrm{MET})$, harvesting $(4.8 \pm 0.6 \mathrm{MET})$, watering $(4.6 \pm 1.1 \mathrm{MET})$, mixing growing medium $(4.3 \pm 0.6 \mathrm{MET})$, and planting transplants $(4.3 \pm 0.5 \mathrm{MET})$ were moderate-intensity physical activities. The tasks such as watering and mixing growing medium were less intense than the other gardening tasks performed in this study $(\mathrm{F}=8.62, P<$ $0.0001)$. There was no difference for exercise intensity of various gardening tasks tested between boys and girls in this study (data not shown).
The exercise intensity associated with gardening tasks may differ because of age, gender, body mass, functional capacity, kinds of garden tools, methods of gardening, or garden conditions (Abadi et al., 2010; Ainsworth et al., 2000; Norton et al., 2010; Park et al., 2011). When comparing the exercise intensities of gardening tasks, the MET values are found to differ according to age group. Younger individuals showed higher MET values for most of the gardening tasks, in comparison with adults in their twenties or older adults over 65 years of age. In previous studies, the average range of MET values of the same gardening tasks that were performed by Korean adults in their twenties $(3.5 \pm 0.5$ to $6.3 \pm 1.2 \mathrm{MET})$ were slightly lower than in children (Park et al., 2012a) (Table 3 ). With regard to older adults, common gardening tasks were judged as low- to moderate-intensity physical activities in American ( $1.6 \pm 0.5$ to $3.6 \pm 0.8 \mathrm{MET}$ ) or Korean adults 
( $1.7 \pm 0.4$ to $4.5 \pm 1.2 \mathrm{MET})$ over 65 years of age (Park et al., 2008a, 2011, $2012 b$ ), and the average range of MET for gardening tasks was lower than those in children (Table 3 ) or adults in their twenties (Park et al., 2012a). The exercise intensity of typical physical activities may also differ due to age. Harrell et al. (2005) reported that the METs values for walking (3.5 mph) was 7.02 MET in children aged 8 to 11 years and 5.78 MET in the children 13 to 15 years. Running
(5 mph) was 11.0 MET in the children aged 8 to 11 years and 10.35 MET in the children 13 to 15 years (Harrell et al., 2005).

Among the various common gardening tasks, digging was more intense when compared with the other gardening tasks in adults in their twenties, older adults over 65 years, and children aged 11 to 13 years (Table 3) (Park et al., 2008a, 2011, $2012 \mathrm{~b}$ ). Tasks such as raking, mulching, and hand weeding were low- to

Table 2. Descriptive information of children whom participated in the study to determine exercise intensities of selected gardening tasks.

\begin{tabular}{|c|c|c|}
\hline \multirow[b]{2}{*}{$\underline{\text { Variable }}$} & \multicolumn{2}{|c|}{ Children $(N=17)$} \\
\hline & Mean & SD \\
\hline Age (years) & 12.4 & 0.7 \\
\hline Height $(\mathrm{cm})^{\mathrm{z}}$ & 146.9 & 4.8 \\
\hline Body weight $(\mathrm{kg})^{\mathrm{y}}$ & 45.8 & 11.0 \\
\hline \multicolumn{3}{|l|}{ Body composition } \\
\hline Body mass index $\left(\mathrm{kg} \cdot \mathrm{m}^{-2}\right)$ & 21.6 & 4.0 \\
\hline Fat $(g)^{y}$ & $9,587.5$ & $6,336.9$ \\
\hline Lean $(g)^{y}$ & $34,706.3$ & $4,067.2$ \\
\hline Percent fat $(\%)^{\mathrm{y}}$ & 19.0 & 8.8 \\
\hline \multicolumn{3}{|l|}{ Resting metabolic rate ${ }^{x}$} \\
\hline $\mathrm{VO}_{2}\left(\mathrm{~mL} \cdot \mathrm{kg}^{-1} \cdot \mathrm{min}^{-1}\right)^{\mathrm{w}}$ & 7.7 & 1.5 \\
\hline Energy expenditure $\left(\mathrm{kJ} \cdot \mathrm{kg}^{-1} \cdot \mathrm{h}^{-1}\right)^{\mathrm{v}}$ & 9.3 & 1.8 \\
\hline Resting metabolic equivalents $(\mathrm{MET})^{\mathrm{u}}$ & 2.2 & 0.4 \\
\hline Resting heart rate $(\mathrm{HR})$ (beats $/ \mathrm{min})^{\mathrm{x}}$ & 97.7 & 11.5 \\
\hline Age-adjusted HRmax (beats $/ \min )^{t}$ & 199.4 & 0.5 \\
\hline \multicolumn{3}{|c|}{ 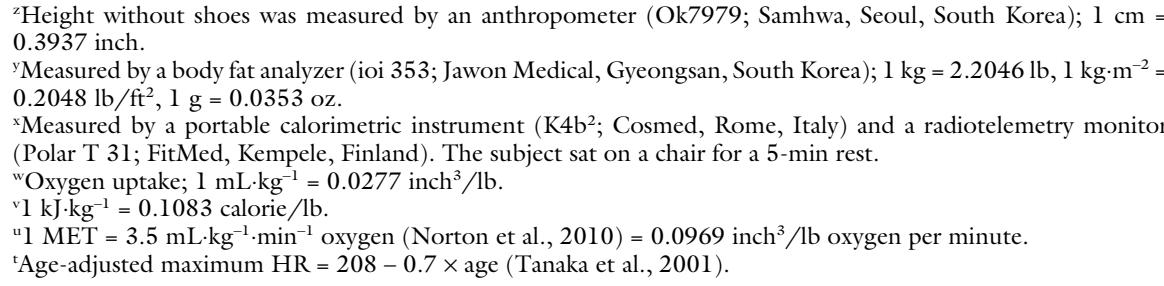 } \\
\hline
\end{tabular}

moderate-intensity physical activities in older adults over 65 years of age (Park et al., 2008a, 2011), but these were moderate- to high-intensity physical activities in adults in their twenties (Park et al., 2012a) and children between 11 and 13 years old in this study (Table 3 ). Transplanting plants, mixing soil, and filling containers with soil were low-intensity physical activities in older adults (Park et al., 2008a, 2011 ) and moderate-intensity activities in adults in their twenties (Park et al., 2012a) and children (Table 3). Sowing seeds, watering using a watering can or hose, and harvesting produce were low-intensity activities in older adults (Park et al., 2011) and moderate-intensity activities in adults in their twenties (Park et al., 2012a) and children (Table 3 ). The gardening tasks that actively used the upper and lower body with a heavy tool were more intense than the tasks that mainly used the upper body, involved standing or sitting, and involved little movement during the task.

In conclusion, this is unique research-based data for MET of various gardening tasks in children by using a portable measurement tool with a high accuracy and validity. The results support the anecdotal evidence for gardening as a physical activity for health in children. Children can use gardening to meet the physical activity recommendation for health benefits (at least $60 \mathrm{~min}$ of moderate to vigorous-intensity physical activity). Gardening interventions may lead to the same health benefits as other types of physical activities. Moreover, in

Table 3. Metabolic measurements of children aged 11 to 13 years whom participated in the study to determine exercise intensities of selected gardening tasks.

\begin{tabular}{|c|c|c|c|c|c|}
\hline \multirow[b]{2}{*}{ Gardening task } & \multicolumn{5}{|c|}{ Mean (SD) } \\
\hline & $\begin{array}{c}\text { Metabolic equivalents } \\
(\mathrm{MET})^{\mathrm{z}}\end{array}$ & $\begin{array}{c}\mathrm{VO}_{2} \\
\left(\mathrm{~mL} \cdot \mathrm{kg}^{-1} \cdot \min ^{-1}\right)^{\mathrm{y}}\end{array}$ & $\begin{array}{l}\text { Heart rate } \\
\text { (beats } / \mathrm{min})\end{array}$ & $\begin{array}{l}\text { Energy expenditure } \\
\left(\mathrm{kJ} \cdot \mathrm{kg}^{-1} \cdot \mathrm{h}^{-1}\right)^{\mathrm{x}}\end{array}$ & $\begin{array}{c}\mathrm{HRmax} \\
(\%)^{\mathrm{w}}\end{array}$ \\
\hline Raking & $6.2(1.5) \mathrm{ab}$ & $21.7(5.4) \mathrm{ab}$ & $135.8(13.0) \mathrm{a}$ & $26.2(6.5) \mathrm{ab}$ & $37.7(9.8) \mathrm{a}$ \\
\hline Weeding & $5.8(1.1) \mathrm{abc}$ & $20.2(4.0) \mathrm{abc}$ & $123.9(14.3) \mathrm{a}$ & $24.1(4.7) \mathrm{abc}$ & $25.7(11.9) \mathrm{ab}$ \\
\hline Mulching & $5.5(1.3) \mathrm{abc}$ & $19.2(4.7) \mathrm{abc}$ & $121.6(16.4) \mathrm{a}$ & $23.0(5.3) \mathrm{abc}$ & $24.6(13.7) \mathrm{ab}$ \\
\hline Harvesting & $4.9(0.6) b c$ & $17.0(2.1) b c$ & $119.6(12.6) \mathrm{a}$ & $20.7(3.0) b c$ & $23.5(8.6) \mathrm{ab}$ \\
\hline Watering & $4.6(1.1) \mathrm{c}$ & $16.1(3.7) \mathrm{c}$ & $121.5(9.9) \mathrm{a}$ & $19.4(4.3) \mathrm{c}$ & $23.1(10.5) \mathrm{ab}$ \\
\hline Mixing growing medium & $4.4(0.6) c$ & $15.3(2.2) \mathrm{c}$ & $119.4(15.1) \mathrm{a}$ & $18.6(3.4) \mathrm{c}$ & $26.0(10.1) \mathrm{ab}$ \\
\hline Planting transplants & $4.3(0.5) c$ & $15.0(1.7) \mathrm{c}$ & $113.7(12.4) \mathrm{a}$ & $18.1(1.8) \mathrm{c}$ & $16.5(13.3) b$ \\
\hline
\end{tabular}

${ }^{2} 1 \mathrm{MET}=3.5 \mathrm{~mL} \cdot \mathrm{kg}^{-1} \cdot \mathrm{min}^{-1}$ oxygen (Norton et al., 2010) $=0.0969 \mathrm{inch}^{3} / \mathrm{lb}$ oxygen per minute.

yxygen uptake; $1 \mathrm{~mL} \cdot \mathrm{kg}^{-1}=0.0277 \mathrm{inch}^{3} / \mathrm{lb}$

${ }^{\mathrm{x}} \mathrm{l} \mathrm{kJ} \cdot \mathrm{kg}^{-1}=0.1083$ calorie $/ \mathrm{lb}$.

"Maximum heart rate $(H R \max )=208-0.7 \times$ age $($ Tanaka et al., 2001). Age-adjusted HRmax was $207.6 \pm 0.7$ beats $/$ min $($ Table 2$)$.

${ }^{v}$ Means sharing a common letter are not significantly different by Scheffé test at $P=0.05$. 
comparison with indoor activities, outdoor activities such as gardening may help to maintain motivation for participating in an exercise intervention and make children physically active (Bird, 2004; Department of Health, 2004; Park et al., 2008a, 2009). Seasonal variations and plant growth cycles also contribute to maintaining motivation for participating in a gardening exercise intervention (Park et al., 2008b).

It would be interesting to compare the exercise intensity of gardening activities with formal physical activities such as walking or jogging. Future studies need to determine the effect of a gardening exercise program on promoting the health conditions of children and making them physically active. Moreover, the MET data for various gardening activities in children can be useful information when a garden-based therapeutic intervention is designed for the children with low levels of physical ability for improving physical functional health conditions.

\section{Literature cited}

Abadi, F., O. Gimenez, R. Arlettaz, and M. Schaub. 2010. An assessment of integrated population models: Bias, accuracy, and violation of the assumption of independence. Ecology 91:7-14.

Ainsworth, B.E., W.L. Haskell, S.D. Herrmann, N. Meckes, D.R. Bassett, Jr., C. Tudor-Locke, J.L. Greer, J. Vezina, M.C. Whitt-Glover, and A.S. Leon. 2011. 2011 compendium of physical activities: A second update of codes and MET values. Med. Sci. Sports Exerc. 43:1575-1581.

Ainsworth, B.E., W.L. Haskell, M.C. Whitt, M.L. Irwin, A.M. Swartz, S.J. Strath, W.L. O'Brien, D.R. Bassett, Jr., K.H. Schmitz, P.O. Emplaincourt, D.R. Jacobs, Jr., and A.S. Leon. 2000. Compendium of physical activities: An update of activity codes and MET intensities. Med. Sci. Sports Exerc. 32:S498-S504.

Atwal, S., J. Porter, and P. MacDonald. 2002. Cardiovascular effects of strenuous exercise in adult recreational hockey: The hockey heart study. Can. Medical Assn. J. 166:303-307.

Baranowski, T., R. Buday, D.I. Thompson, and J. Baranowski. 2008. Playing for real: Video games and stories for health-related behavior change. Amer. J. Prev. Med. 34:74-82.

Biddle, S., N. Cavill, and J.F. Sallis. 1998. Young and active? Young people and health-enhancing physical activity: Evidence and implications. 1st ed. Health Educ. Authority, London, UK.

Bird, W. 2004. Natural fit: Can green space and biodiversity increase levels of physical activity? Royal Soc. Protection Birds, London, UK.

Borra, S.T., N. Schwartz, C.G. Spain, and M. Natchipolsky. 1995. Food, physical activity, and fun: Inspiring America's kids to more healthful lifestyles. J. Amer. Dietetic Assn. 95:816-823.

Bundred, P., D. Kitchiner, and I. Buchan. 2001. Prevalence of overweight and obese children between 1989 and 1998: Population based series of cross sectional studies. BMJ 322:326-328.

Burdette, H.L. and R.C. Whitaker. 2005. A national study of neighborhood safety, outdoor play, television viewing, and obesity in preschool children. Pediatrics 116:657-662.

Caspersen, C.J., K.E. Powell, and G.M. Christenson. 1985. Physical activity, exercise, and physical fitness: Definitions and distinctions for health-related research. Public Health Rep. 100:126131.

Department of Health. 2004. At least 5 a week: Physical activity and health outcomes: A review of the chief medical officer. Dept. Health, London, UK.

Dirks, A.E. and K. Orvis. 2005. An evaluation of the junior master gardener program in third grade classrooms. HortTechnology 15:443-447.

Doyon, K.H., S. Perrey, D. Abe, and R.L. Hughson. 2001. Field testing of $\mathrm{VO}_{2}$ peak in cross-country skiers with portable breath-by-breath system. Can. J. Appl. Physiol. 26:1-11.

Epstein, L.H., M.D. Beecher, J.L. Graf, and J.N. Roemmich. 2007. Choice of interactive dance and bicycle games in overweight and nonoverweight youth. Ann. Behav. Med. 33:124-131.

Gunn, S.M., A.G. Brooks, R.T. Withers, C.J. Gore, J.L. Plummer, and J. Cormack. 2005. The energy cost of household and garden activities in 55-to 65-year-old males. Eur. J. Appl. Physiol. 94:476486.

Harrell, J.S., R.G. McMurray, C.D. Baggett, M.L. Pennell, P.F. Pearce, and S.I. Bangdiwala. 2005. Energy costs of physical activities in children and adolescents. Med. Sci. Sports Exerc. 37:329-336.

Kawakami, Y., D. Nozaki, A. Matsuo, and T. Fukunaga. 1992. Reliability of measurement of oxygen uptake by a portable telemetric system. Eur. J. Appl. Physiol. 65:409-414.
Klemmer, C.D., T.M. Waliczek, and J.M. Zajicek. 2005a. Development of science achievement evaluation instrument for a school garden program. HortTechnology 15:433-438.

Klemmer, C.D., T.M. Waliczek, and J.M. Zajicek. 2005b. Growing minds: The effect of a school gardening program on the science achievement of elementary students. Hort Technology 15:448-452.

Lineberger, S.E. and J.M. Zajicek. 2000. School gardens: Can a hand-on teaching tool affect students' attitudes and behaviors regarding fruits and vegetables? HortTechnology 10:593-597.

London, R.A. and O. Gurantz. 2013. Afterschool program participation youth physical fitness, and overweight. Amer. J. Prev. Med. 44:200-207.

Mabie, R. and M. Baker. 1996. The influence of experiential instruction on urban elementary students' knowledge of the food and fiber system. J. Ext. 34(6): 1-4.

Malina, R.M. 2001. Physical activity and fitness: Pathways from childhood to adulthood. Amer. J. Hum. Biol. 13:162172.

McAleese, J.D. and L.L. Rankin. 2007. Garden based nutrition education affects fruit and vegetable consumption in the sixth grade adolescents. J. Amer. Dietetic Assn. 107:662-665.

McCue, M., K. Marlatt, J. Sirard, and D. Dengel. 2013. Examination of changes in youth diet and physical activity over the summer vacation period. Internet J. Allied Health Sci. Practice 11(1):1-6.

McLaughlin, J.E., G.A. King, E.T. Howley, D.R. Bassett, and B.E. Ainsworth. 2001. Validation of the Cosmed $\mathrm{K} \mathrm{b}^{2}$ portable metabolic system. Intl. J. Sports Med. 22:280-284.

Mellecker, R.R. and A.M. McManus. 2008. Energy expenditure and cardiovascular responses to seated and active gaming in children. Arch. Pediatr. Adolesc. Med. 162:886-891.

Montessori, M. 1964. The Montessori method. Schocken Books, Amsterdam, The Netherlands.

Morris, J.L., M. Briggs, and S. ZidenbergCherr. 2000. School-based gardens can teach kinds healthier eating habits. Calif. Agr. 54(5):40-46.

Morris, J.L., A. Neustadter, and S. Zidenberg-Cherr. 2001. First-grade gardeners more likely to taste vegetables. Calif. Agr. 55(1):43-46.

Morris, J.L. and S. Zidenberg-Cherr. 2002. Garden-enhanced nutrition curriculum 
improves fourth-grade school children's knowledge of nutrition and preferences for some vegetables. J. Amer. Dietetic Assn. 102:91-93.

Norman, G.J., B.A. Schmid, J.F. Sallis, K.J. Calfas, and K. Patrick. 2005. Psychosocial and environmental correlates of adolescent sedentary behaviors. Pediatrics 116:908-916.

Norton, K., L. Norton, and D. Sadgrove. 2010. Position statement on physical activity and exercise intensity terminology. J. Sci. Med. Sport 13:496-502.

O'Dea, J.A. 2003. Why do kids eat healthful food? Perceived benefits of and barriers to healthful eating and physical activity among children and adolescents. J. Amer. Dietetic Assn. 103:497-501.

Park, S.A., A.Y. Lee, K.S. Lee, H.S. Lee, J.E. Song, B.R. Kim, K.C. Son, and C.A. Shoemaker. 2012a. Metabolic equivalents of gardening tasks as a physical activity in children and adults. Korean J. Hort. Sci. Technol. 30:181S. (abstr.).

Park, S.A., K.S. Lee, and K.C. Son. 2011. Determining exercise intensities of gardening tasks as a physical activity using metabolic equivalents in older adults. HortScience 46:1706-1710.

Park, S.A., K.S. Lee, K.C. Son, and C.A. Shoemaker. 2012b. Metabolic cost of horticulture activities in older adults. J. Jpn. Soc. Hort. Sci. 81:295-299.

Park, S.A., C.A. Shoemaker, and M.D. Haub. 2008a. A preliminary investigation on exercise intensities of gardening tasks in older adults. Percept. Mot. Skills 107: 974-980.
Park, S.A., C.A. Shoemaker, and M.D Haub. 2008b. Can older gardeners meet the physical activity recommendation through gardening? HortTechnology 18:639-643.

Park, S.A., C.A. Shoemaker, and M.D. Haub. 2009. Physical and psychological health conditions of older adults classified as gardeners or nongardeners. HortScience 44:206-210.

Pate, R.R., M. Pratt, S.N. Blair, W.L. Haskell, C.A. Macera, C. Bouchard, D. Buchner, W. Ettinger, G.W. Heath, A.C. King, A. Kriska, A.S. Leon, B.H. Marcus, J. Morris, R.S. Paffenbarger, K. Patrick, M.L. Pollock, J.M. Rippe, J. Sallis, and J.H. Wilmore. 1995. Physical activity and public health: A recommendation from the Centers for Disease Control and Prevention and the American College of Sports Medicine. J. Amer. Medical Assn. 273:402-407.

Rees, R., J. Kavanagh, A. Harden, J. Shepherd, G. Brunton, S. Oliver, and A. Oakley. 2006. Young people and physical activity: A systematic review matching their views to effective interventions. Health Educ. Res. 21:806-825.

Siwik, V., R. Kutob, C. Ritenbaugh, L. Cruz, J. Senf, M. Aickin, S. Going, and A. Shtte. 2013. Intervention in overweight children improves body mass index (BMI) and physical activity. J. Amer. Board Fam. Med. 26:126-137.

Smith, L.L. and C.E. Motsenbocker. 2005. Impact of hands-on science through school gardening in Louisiana public elementary schools. Hort Technology 15: 439-443.
Spear, B.A., S.E. Barlow, C. Ervin, D.S. Ludwig, B.E. Saelens, K.E. Schetzina, and E.M. Taveras. 2007. Recommendations for treatment of child and adolescent overweight and obesity. Pediatrics 120: S254-S288.

Stamatakis, E., P. Primatesta, S. Chinn, R. Rona, and E. Falascheti. 2005. Overweight and obesity trends from 1974 to 2003 in English children: What is the role of socioeconomic factors? Arch. Dis. Child. 90:999-1004.

Strong, W.B., R.M. Malina, C.J.R. Blimkie, S.R. Daniels, R.K. Dishman, B. Gutin, A.C. Hergenroeder, A. Must, P.A. Nixon, J.M. Pivarnik, T. Rowland, S. Trost, and F. Trudeau. 2005. Evidence based physical activity for school-age youth. J. Pediatr. 146:732-737.

Tanaka, H., K.D. Monahan, and D.R. Seals. 2001. Age-predicted maximal heart rate revisited. J. Amer. Coll. Cardiol. 37: 153-156.

Taveras, E.M., A.E. Field, C.S. Berkey, S.L. Rifas-Shiman, A.L. Frazier, G.A. Colditz, and M.W. Gillman. 2007. Longitudinal relationship between television viewing and leisure-time physical activity during adolescence. Pediatrics 119:e314e319.

Telama, R., X. Yang, L. Laakso, and J. Viikari. 1997. Physical activity in childhood and adolescence as predictor of physical activity in young adulthood. Amer. J. Prev. Med. 13:317-323.

U.S. Department of Health and Human Services. 1996. Physical activity and health: A report of the Surgeon General. Dept. Health Human Services, Centers Dis. Control Prevention, Atlanta, GA. 